\title{
Research of the Development Status of Brand Agricultural Products
}

\author{
Xue LI \\ Jilin Agricultural University, Changchun, Jilin, China \\ 50207681@qq.com
}

Li Xue: Jilin Agricultural University, No. 2888, Xincheng Street, Changchun, Jilin, 130000,

1981—, female, Han Nationality, master, lecturer

Key words: brand agricultural products; regional agricultural products

\begin{abstract}
The evaluation of the current situation of Chinese brand agricultural products. According to value assessment reports of regional brands and enterprise brands, it analyzes key elements that play decisive roles in brand agricultural products strategy. According to the research data of Chinese agricultural regional brands, it studies the development status of Chinese agricultural products regional brands and analyzes characteristics and existing problems in development viewpoints, development trend, regional distribution, development speed, category concentration, product chain and management regulation.
\end{abstract}

\section{Introduction}

In 2016, No.1 Document of central government stated that prices of Chinese agricultural products market was decreasing and it was an urgent historical task to improve the competitiveness of agricultural products in international market. However, in the economic environment with rapid development of Internet, it remains an important task to avoid homogeneous competition of low quality and low price agricultural products and realize differential management and further increase consumers' premium willingness to pay. Preliminary results in construction of Chinese brand agricultural products were achieved. According to the transaction data of 2015 mobile Internet, transaction scale of mobile shopping has been rising steadily; mobile terminal relies on cheaper equipment and more convenient operating characteristics compared with PC terminal and will take up increasingly more important status. Therefore, this paper has conducted researches on marketing strategies of brand agricultural products mobile Internet and further promote the development of brand agricultural products as well as the competitiveness in international market of brand agricultural products by relying on the development trend of mobile Internet transaction on the basis of Chinese agricultural products brand strategies at the characteristics of mobile Internet.

1. Researches about Chinese agricultural brand marketing strategies from macroscopic perspective: (1) Humanity factor: taking leisure agriculture as the starting point to promote sales of brand agricultural products (Zhang Yu, 2015) (2) Geographical elements: using characteristics of agricultural brands, which are regionality and publicity, using "mother-child brand mode" to make agricultural products brand. (Hu Xiaoyun, 2014) (3) Social factor: starting from perspectives of agricultural scientific research institutions, agricultural facilitating agency, agricultural administrative service division and agricultural enterprises, improving regional brand competitiveness of agricultural products (Yao Chunling, 2013) (5) Economic factor: establishing modern industry system, improving industrial technological standard and innovation ability, accelerating construction of exclusive agricultural products base (Zhan Yi, 2012) (6) Political factor: the government leads and guides enterprises to form regional brand awareness, maintaining brand images of regional characteristic agricultural products in government's integrating process of characteristic agricultural products brand (Wang Jun, 2014). (7)Technological and environmental 
factor: proposing innovative strategies of agricultural Internet marketing from perspectives of mobile electronic commerce, Internet of Things, customer relation management and so on.

2. From microscopic perspective, it involves: (1) Supplier factor: researches of product image, regional image, consumer image and enterprise image of brand image agricultural products regional brand (Xu Jinan, 2010). It studies marketing strategies of three kinds of agricultural products based on product characteristics, which are natural resources quantity (scale) dependent form, natural resources endowment dependent form and labor resources dependent form (Yu Zhenwei, 2011) (2) Purchaser factor: safe agricultural products value dimension that influence consumers' purchase intention: function value, social value and economic value (Zhang Fangfang, 2013). Researches of label information on male consumers' and female consumers' purchase decisions (Zhang Chuantong, Lu Juan, 2012) (3) Middleman factor: it analyses forming conditions of fresh agricultural products community direct selling model from two aspects, which are demands and provision to optimize fresh agricultural products community direct selling model (Yang Huilian, Huo Xuexi, 2014) (5) Competitor factor: it establishes an assessment indicator system of agricultural products competitiveness, including four aspects, which are production competitiveness, market competitiveness, technology competitiveness and marketing competitiveness (Wan Xing, 2013) (6)Public factor: it discusses problems in the construction of Chinese agricultural products brand from cultural perspective (Chen Lingjun, 2010) (7) Inner-enterprise factor: agricultural products regional public brand and public enterprise self-interest risk assessment model (Lou Xiaodong, 2014)

3. Researches about mobile Internet marketing strategies are reflected in three aspects: (1) Researches about basic concept of mobile Internet: including definitions, functional characteristics and architecture and it discusses mobile terminal, access network, application service, security and privacy (Wu Jiyi, 2015) (2) Researches about consumption characteristics of mobile Internet: typical behaviors of consumers using cellphones to surf the Internet and classification of consumer group (Chen Shun, 2012) (3) Researches about integrated marketing strategy of mobile Internet: pricing method researches in mobile Internet age (Li Fei, 2014); mobile two-dimension code, researches about mobile business district, mobile search and other strategies on stimulating consumers to have direct purchase behaviors (Liao Weihong, 2013); researches about establishing brand consistency from multi-channel or cross-channel to reach effects of integrated marketing communication and improve client consistency experience, client perception value and realizing enterprise value (Tian Li, 2015) (4) Enterprise We-chat marketing researches and strategies analysis (Li Xiangdian, 2014); Characteristics of APP marketing of mobile new technology; common modes, marketing strategies research (Li Xinjing, 2014)

4. Japanese scholar Fujita Masahisa has proposed the concept of brand agriculture and its characteristics completely. He defined brand agriculture on the basis of summarizing "vovp" in the 1960s and "michin eki" in the 1990s. He believed that brand agriculture was "creative natural agriculture including aquatic products, forestry, processing industry and tourism" that was rooted in the land. (Fujita Masahisa, 2003) As to construction of agricultural products brand, Demo·Hayes launched a meaningful research. He believed that because of the small scale and limited productive competence, it was difficult for individual farmers to assume customers' approval and the huge cost produced by imitating brands, so farmers must establish their own brands by the supply method of limiting products to obtain corresponding reasonable profits (Demo•Hayes, 2006) As to agricultural products brand management, Bryan·Williams started from the perspective of export proportion and competitiveness of agricultural products in international market and proposed to manage brands of agricultural products. He believed that competitive advantages of agricultural brands relied on the establishment of a nation's good brand image and a nation's image could be managed to a series of agricultural products to the same brand. (Bryan·Williams, 2007)

In conclusion, researches aiming at Chinese brand agricultural products can start from multi-disciplines and multi-perspectives, which both have macro strategic researches and micro strategic researches; they have also acquired great achievements in empirical researches, such as 
“Yantai Apple” (Lin Derong \& Teng Shuzhen, 2012) "Changbai Mountain Ginseng” (Wang Jun \& Li Xin, 2014). However, researches aiming at brand agricultural products mobile Internet strategic strategies are just in the beginning period, consumers' consumption habits of traditional Internet are turning mobile with each passing day, flows at PC terminal are decreasing and transferring to mobile terminal; e-commerce businessmen following flows are transiting to e-business one after another. Confronted with changes at mobile Internet marketing modes and business modes, theoretical researches published by scholars only stay on the concept, scattered and dispersed researches. Though a few research achievements are from empirical analysis, systemic research achievements based on hierarchy investigation is still not common. Therefore, this paper combines characteristics of mobile Internet, which are convenience of time and place, fragmentization and high interaction, turn mobile terminal to a link, boost brand agricultural products market to develop towards "online + offline", "social contact + consumption", "PC terminal + mobile + TV", "entertainment + consumption" and realize the mode of integrated marketing and air-sharing. It also investigates consumption characteristics of mobile internet deeply and formulates marketing strategies suitable for Chinese brand agricultural products mobile Internet.

\section{Reference}

[1]Sun Qi. Development Trend of Agricultural Products E-commerce from Ali Platform. Business Economics Study, 2015

[2]Cui Lili. Empirical Analysis of Social Innovative Elements Promoting "Taobao Village" E-commerce Development_—_Taking "Lishui Zhejiang” as an Example. Chinese Rural Economy, 2014(3)

[3]Liu Jing. Rural E-commerce Dvelopment Driving Agricultural Management New Mode_—Case Study based on “Taobao Village” in Jiangsu Province

[4]Hu Xiaoyun. Mode Winning_Chinese Leading Enterprises of Agricultural Industrialization Group Image Explanation 3. Zhejiang University Press, 2016

[5]Hu Xiaoyun. Value Remaking_Zhejiang University CARD Chinese Agricultural Brand Research Center Chinese Agricultural Brand Strategic Planning Anthology. Zhejiang University Press, 2016

[6]Achilleas Kontogeorgos 《Brands, quality badges and agricultural cooperatives: how can they co-exist?》(Emerald Journal) (2012)

12. Byung-Oh LEE《Quality and Safety Control System of Agricultural Products in Korea》 